\title{
Deixis as a symbolic phenomenon
}

\author{
Donna E. West (Cortland, NY)
}

\begin{abstract}
Children's early development of demonstrative use emanates directly from indexical gestures, namely, eye gaze, pointing, prehensile reaching, and giving exchanges. These indexical gestures become social in that they are joint attentional, and mark the inception of deictic use. Although children's deictic use draws upon index as a directional and social phenomenon, early uses of index alone do not deliver any semantic/lexical/symbolic determinants to the mix. The distinctive premise here is that deictics, especially demonstratives, are not merely social, but symbolic from a Peircian perspective, especially in light of developmental findings (West 1986, 1987, 2010; Tanz 2009) indicating an acquisitional pattern of non-contrastive to contrastive uses of "this" and "that" from 3;0-4;9. While initial non-contrastive uses of demonstratives are directional and/or social, contrastive use after 3;0 requires apprehension of symbolic role taking/role shifting.

In addition to delivering the indexical and/or social, deictic indicators must implicitly refer to a class (Nunberg 1993, 1995), e.g., near/far objects from speaker's perspective in the case of demonstratives, and must ultimately have the potential to contrast objects/places with respect to distinctive points of orientation. These components together illustrate how mastery of deictic indicators is both a socio-pragmatic and semantic enterprise. In addition to indexing objects and securing joint attention with gesture, deixis requires semiotic and semantically based orientational competencies to shift perspectives and speech situation roles.
\end{abstract}

\section{$1 \quad$ Introduction}

Much attention has been accorded to the role of joint attention in the early use of demonstratives and how it is that pointing is a gestural precursor and bridge to the emergence of space deictics. Joint attention schemes require a social component wherein at least one individual secures a focus for him/her self first and thereafter attempts to influence the other to focus on the same object. The primary purpose of joint attention is communication toward language emergence, which is especially relevant to the emergence of demonstrative pronouns. The trend in the literature is that early gestures instrumental in securing joint attention are characterized as deictic before language and social reciprocity even develop, and emergent demonstrative pronoun uses are perceived to be deictic without question. Deictic and indexical are often used interchangeably in the literature to refer to the directional nature of the gesture/demonstrative toward an object of focus.

The case is initially made that necessary to deictic use but not sufficient, is apprehension of bidirectional role taking exchanges. Afterward, a discussion of how deictic use becomes symbolic in the semiotic sense is set forth to characterize further deictic development. The use of early gestures and demonstratives does not qualify as deictic. The contention that deictic use consists in more than the indexical function is further supported with an analysis of the ontogeny of specific indexical gestures and demonstrative pronoun use; thus, developmental 
trends are highlighted and discussed in support of children's early use of index, which later becomes joint attentional and deictic.

\section{$2 \quad$ What qualifies as deictic?}

"Index" appears to have replaced or at least has become entirely synonymous with the concept of deixis of late (Bates 1976; Carpenter, Mastergeorge \& Coggins 1983; Crais, Douglas \& Campbell 2004). The emphasis often is on the derivation of deixis from the Greek as indicating the function of "pointing out" (Lyons 1995: 303). While indexicality is a necessary component of deixis in that the linguistic/physical/cognitive contexts are primary to their interpretations, indexicality alone is insufficient to qualify as deictic. It appears that early indexical gestures and even emergent demonstrative and speaker pronouns consist in their indexical use in a socially motivated context only apart from apprehension/application of their nature as having a general meaning in the code (from a Jakobsonian perspective which draws on a Peircian framework). In addition to indexical qualities, deictics must include a general/symbolic meaning which considers the social and reciprocal role of the referent.

Within the last fifteen years (Lyons 1995; Diessel 1999, 2006; Levinson 2002, 2004), deixis has been extended to apply to virtually every linguistic utterance and even to pre-linguistic gestures, namely eye gaze, pointing, giving, and the like. To illustrate the former, Lyons (1995: 269) states that "the vast majority of utterance-inscriptions in most languages are implicitly, if not explicitly, indexical or deictic." The focus in this inquiry is primarily the latter, which results in application of deixis to pre-linguistic behaviors alone, especially to certain gestures, particularly pointing. Volterra et. al. (2005: 211) and Zinober and Martlew (1985: 304) claim that until gestures are used declaratively (in joint attention schemes) they are not deictic. Imperative gestures do not qualify as deictic since they request an object; and they appear earlier on in ontogeny, according to Zinober and Martlew (1985: 304). Bates is one of the first to claim that early (fourteen months of age) primitive indexically based social actions without linguistic accompaniment (declarative performative), such as pointing schemes, constitute deictic use: "This series of steps-point at object, point at adult, point at object- put together in a chain form the components that eventually form the smooth deictic act of simultaneously pointing at an object while turning to the other for confirmation" (Bates 1976: 303). Bates appears to require the presence of social exchange in joint attentional schemes to constitute deictic use, although this claim is not explicit.

Pointing is not the only early gesture which other investigators (Crais, Douglas \& Campbell 2004; Thal \& Tobias 1992; Volterra, Caselli, Capirici \& Pizzuto 2005; Levinson 2004; Pizzuto \& Copabianco 2008) consider to be deictic. ${ }^{1}$ Reaching with the open hand toward another, giving, showing, and pushing another person or object away from the child without linguistic accompaniment have been recently categorized as deictic based on the rationale that they are directional/indexical and perhaps upon the rationale that they are socially motivated in that they are joint attentional. Crais, Douglas and Campbell (2004: 681) extend deictic use even to such behaviors as Bruner's joint attention function, indicating that socially motivated eye gaze likewise is deictic. Using the same rationale, namely, that indexical/directional gesture is equivalent to deictic use, Volterra et. al. (2005: 9-10) likewise consider gesturally directional performatives, e.g., giving, showing, pointing, ritualized requests, to be deictic gestures since giving illustrates the trajectory of object transfer between giver and receiver. In fact, these investigators in keeping with current trends "reanalyze and reclassify [all performatives] as deictic," (Volterra et. al. 2005: 9) those which are declarative as well as

\footnotetext{
${ }^{1}$ Levinson $(2004$, p. 102) claims that "a nod of the head or in some cultures pursing of the lips" are also deictic gestures.
} 
imperative. Implicit in what qualifies as deictic is the reoccuring theme of social exchange when the child is affecting another, either to modify another's attention/conduct; to secure a sought after object for the child him or her self; and/or to make a statement/assertion about the functionality/identity of the object. This social, indexical function appears to define 'performatives' as well as early deictic use for these investigators ${ }^{2}$. Absent from their analysis is whether these early social, directional gestural schemes qualify as symbolic and reciprocal.

Until a more extended semiotic meaning is ascertained with the advent of symbolic use, at least on an unconscious level, each use of index, be it gestural or emergent linguistic, is devoid of a potentially shifting character. In other words, early eye gaze, reaching, or pointing, even if they are intentional (fixing deliberately on a particular referent) may be nonshifting absent their social/conventional meaning. Even deictic terms can be used nondeictically if their use is devoid of symbolic meaning (cf. Section 5). If socially motivated performatives are initiated absent recognition of a conventional meaning they are indexical only and not symbolic. Similarly, if eye gaze, prehension, or pointing fail to include the general meaning of object focus/securing another's focus to that of the child, index has but a single purpose (joint attention) and shifting attention to distinctive objects is unrecognized. The indexical meaning of these gestures, namely, focus/attention to their referent or protoimperatives/declaratives, is a necessary component of deictic use, but is still insufficient. Focus on one referent assumes a lack of focus on others and the potentiality of subsequent, distinctive foci, hence an absence of some incorporation of symbolic/conventional meaning. A single focus having the potential to shift from a single orientation or from a single participant's notice is but a rudimentary illustration of what deictic use entails. Merely gesturing toward an object/person or using a linguistic shifter as index does not constitute deictic use. The gesture/ linguistic shifter must, at very least, be iteratively imitative of a recognizable convention, drawing on symbolic/conventional meaning. Indexical gestures are indexical only without reference to a symbolic shifting system; and even some linguistic terms which have the potential to draw upon symbolic meaning may be used indexically only, especially by children.

\section{Gestural precursors to deictic use}

Certain gestural schemes precede social and non-social pointing in ontogeny and are the foundation for the development of joint attention schemes (see appendix A). In any case, none of the gestural schemes, be they joint attentional or not, are deictic. Eye gaze is the first gesture which serves as a precursor to deictic use. It develops during the first two months according to Scaife and Bruner (1975: 265) and appears to constitute the earliest proto-index underlying the development of joint attentional schemes. At this stage, eye gaze appears to fall short of a full fledged index in that it is not self initiated, nor does it single out an object/person. Gaze following at two months of age does not yet clearly constitute a joint attention scheme in that it is not socially motivated (Butterworth \& Jarrett 1991: 57). Without focus on a single object from among a host of potential objects, as is the case in this early gaze following scheme, joint attention is not established.

Infants' prehensile facility demonstrates their means to individually focus on an object, which according to Carpenter, Nagell and Tomasello (1998: 152) is a primary factor in developing joint attention schemes. When eye gaze becomes joint it ultimately unites spatial and temporal

\footnotetext{
2 Whereas the purpose of declarative performatives is to demonstrate the utility or to identify an object, in a social context, the purpose of social performatives is to secure the object for the child him or her self. Often it is difficult to determine which type of performative is operating and whether it may or may not be operating simultaneously. Hence, current trend is to classify both as deictic as opposed to the former, for which social interaction is necessary.
} 
components of the environment, both physically and socially. Unity of spatial and temporal components is not obvious without "an object directed process" (Carpenter et al. 1998: 152) such as intentional reaching. Eye gaze is still a proto-index at the point at which prehensile reach is developed, since it lacks the joint/social gaze component. Nonetheless, prehension hastens object recognition and discovery which Carpenter et al. (1998: 153) consider to be foundational to the onset of joint attentional schemes.

While at its inception of use infants' directional eye gaze constitutes but a proto-index, in its more full fledged use within prehensile schemes, it becomes an indexical gesture, for the child alone. In normal children, eye gaze and directed intentional reaching are indexes individually and as coordinated schemes since gaze must guide reach. At approximately four-months-ofage through eight months, children's intentional reach/ prehensile grasping is often for the child alone (Bates 1976: 61; 1979: 103) and serves as an indexical gesture for the child alone. Intentional reaching illustrates a less ambiguous and more effective means of singling out objects in the environment than does eye gaze since objects are grasped one at a time, whereas eye gaze often encompasses more than one object simultaneously - the intended object of focus may not be obvious. Intentional reaching guided by directional gaze constitutes an indexical gesture since it complies with the necessary components of index. Indexes possess two primary attributes: 1.) they refer to an individual person/object/group and 2.) they "direct the attention to their objects" (CP 2.306). Since intentional reach toward a particular object requires the child to attend to one object from among others, reaching is obviously indexical. Attending to one object and not another demonstrates that the infant has singled out an object for focus as a consequence of proximity and/or salient properties. This singling out is a basic and necessary property of index, leading to the development of joint attention. Prehensile reaching lacks reciprocity and a definitive apprehension of the nature of participant roles; despite its indexical function, it is nonetheless presocial and non-deictic.

Showing and giving gestures likewise are indexical and serve as bridges to joint attentional schemes. Showing and giving consist of a static unidirectional object transfer in which the child takes the role of giver only or shower only. These early social skills of showing and giving appear to lay the groundwork for developing relational competencies not merely those inherent to spatial orientations and contrasts but those necessary for conversational turn taking. At eight to nine months of age this unidirectional trajectory of giving and showing from child to other validates the indexical yet non-reciprocal nature of these gestures (Bates 1976: 61). Between nine and eleven months, children begin extending the arm and hand to receive/take for social purposes (Carpenter et al. 1998: 681; Volterra, Caselli, Capirci \& Pizzuto 2005: 9). Extending the arm and hand amplifies the use of indexical gestures in that the array of objects which can be indexed is larger. Giving exchanges permit children to obtain objects which were beyond their initial reach. At eleven months of age, giving exchanges are not merely unidirectional but become bidirectional when children show and are shown, and give to and receive from the extended hand and arm of another, which appears to facilitate the social element of joint attention schemes.

It is not until eighteen months of age when eye gaze without additional accompanying gestures becomes unequivocally joint attentional between the child and the adult: "This new ability to isolate the referent of the mother's gaze, as plotted from the infant's position... is definitely present at 18 months" (Butterworth et al. 1991: 63). This indicates that joint eye gaze does not serve as a social index until eighteen months of age when it goes beyond following another's gaze alteration by isolating and validating another's object of focus. At this point in ontogeny, eye gaze becomes a social index differentiating self from other as a source for the indexical gesture, establishing bidirectional gestural schemes and bidirectional focus on objects. 
The purpose of indexical gestures evolves from a pre-social function at two months of age when children follow an alteration in gaze trajectory and direct their attention toward a referent object to a social function (Bates 1976: 61) indicating to another his or her attention/focus on a referent object and even exchanging the referent object. This social purpose materializes after nine months of age when children secure the cooperation/attention/focus of another and when their exchange of objects and gaze trajectory are bidirectional (Bates 1979: 34-35). The social function of these indexical gestures assumes that the producer of the gesture can be the child or another who intends to direct the attention of another toward the producer's object of focus. According to Levinson (2004: 101), instantiations of "indexicality [are] both an intentional and attentional phenomenon."3

The earliest uses of index ${ }^{4}$ manifest themselves in gestures unaccompanied by language. Early indexical gestures derive their meaning from the extra-linguistic context, before shared knowledge between speech partners is established. Eye gaze, pointing and the like, are important in tracing the emergence of index, pre-linguistically and pre-socially, and in demonstrating the role that index plays in the development of deictics once language and social reciprocity emerge. Children's early uses of gesture do not yet include a social or symbolic function. Although, early on, the indexical coordinates with the iconic, any general meaning, as in object classes, is unapprehended. Because the indexical use is necessary but not sufficient to deictic use, disentangling it from symbolic use in ontogeny can shed light on what constitutes deictic use and what merely serves as an indexical precursor to such use.

\section{Early use of demonstratives}

The earliest uses of demonstrative pronouns are accompanied by indexical gestures, primarily pointing (Clark 2009: 94). In fact, the gesture precedes initial demonstrative productions and serves as a "boot-strapping function" (Goldin-Meadow 2003: 210). These earliest indexical expressions are one word utterances belonging to the class of demonstratives, specifically demonstrative pronouns (Clark 2009: 94). These earliest demonstrative pronouns accompanied by gesture are, nonetheless, non-deictic and non-social; as long as gestures, such as pointing, accompany early demonstrative use their non-deictic character persists. According to Bates (1976: 55, 61) and Clark (2009: 94) demonstratives derive from pointing gestures and serve as precursors to early space deictic use in English; and afterward pointing merely accompanies demonstrative use disambiguating which referent is the focus (Clark 1978: 96-97; Diessel 1999: 110; 2006: 466). The very need for disambiguation highlights the non-deictic character of demonstrative use. Reliance on visual indexes, such as pointing, accentuates indexical meaning to the exclusion of symbolic meaning. With little dependence on the linguistic expression to determine the utterances' meaning/referent, what is left for the speech partners is the visual/directional indicator whose function is to single out an object in a joint attention scheme. Dependence on an objects' membership in a class of similarly or differently situated objects from points of orientation which can shift, rests upon more complex cognitive and linguistic skills.

Accompaniment of initial demonstrative productions with gestural indexes is likely to be a consequence of two factors: early exophoric demonstrative use (Diessel 2006: 470) and the nature of demonstratives as expressing definiteness. The latter characterizes the function of demonstratives to identify a specific referent (Lyons 1968: 279). With respect to the former

\footnotetext{
3 Indexicality is a purely human phenomenon since the component of intentionality appears to be absent in chimpanzee's pointing (Povinelli, Bering \& Giambrone 2004: 40).

4 Index is used in the Peircian sense of singling out one referent/contextual element from other potential referents. The interpretation of index wholly depends on contextual signs/indicators, which coexist in the same spatio-temporal environment with the referent.
} 
(exophoric demonstrative use) referents of "this" or "that" are typically present in the extralinguistic context (Halliday and Hassan 1976: 58-59). Even when the referent is not present at the time that the demonstrative pronoun is produced with a gesture, its use is still exophoric since according to Bühler (1932/1990: 156) and Fricke (2002: 221-222) a contextual analogy based on its original use is reproduced in the present context. This reference to absent objects is still exophoric because it is "anchored... to the current origo, to the here and now of the interlocutors" (Haviland 2000: 19). As long as the origo of the exophoric reference is in the here and now, the referent need not be present (West 2011).

Moreover, if the demonstrative pronoun refers to any object of focus without implicitly alluding to speaker as origo (or origo's possible orientations) or contrastive near/far locations, as is the case in their non-deictic and non-social uses, indexical gestures need to compensate for the lack of linguistic specificity. The meaning of the linguistic cues in the form of demonstrative pronouns is so vague as to be an ineffectual indexical device, obviating the need for inclusion of gesture. An explanation for their primary character is the ease and commonality of relying on visual non-linguistic cues, or gestures, in joint attention schemes. In fact, Goldin-Meadow (2003: 80) claims that the purpose of gesture in exophoric deictic use is to disambiguate which referent is the object of focus, especially in contrastive contexts when at least two objects are potential referents.

The unmarked use is prevalent in exophoric uses, when the demonstratives are used noncontrastively, that is non-deictically. ${ }^{5}$ "This" is more often marked and is virtually always restricted to contrastive contexts and its use is more often exophoric (Lyons 1977: 311; Tanz 2009: 79-81). If there is but one referent of focus and one spatial orientation "that" is the demonstrative selected for use, be it exophoric, endophoric or shared knowledge based; and "that" is unmarked since it refers to any object beyond proximate space in its contrastive use, and in its non-contrastive use, to any object under focus independent of proximity to any one origo. It is clear that "that" is the unmarked ${ }^{6}$ member of the demonstrative paradigm in that it has a wider incidence of use and is produced earlier on in ontogeny when compared to "this"7 (West 1986: 115; Tanz 2009: 87, 125). In contrast, "this" appears in restricted contexts (proximate, contrastive use from speaker's perspective).

Findings which support the ontogeny of exophoric use from the unmarked demonstrative pronoun "that" only to the more marked demonstrative pronoun uses of "this" and "that" are derived from two sources: early data (from 1;6-3;4) from the author's 1986 study and data from Tanz's (2009) study in which subjects range in age from 3;4-4;9. The design of the former study (West, 1986) consisted of a natural speech sample and a cognitive task. In the cognitive task, the child was asked to find the candy under one of two cups arranged at different distances from the child/experimenter. There were eight trials, four of which included "this" and four of which included "that"; in four of the trials the child and experimenter sat adjacent to one another such that they shared the same orientation to the objects, whereas in the other four trials, orientations to the objects were distinct (child and experimenter facing one another across a table). The experimenter instructed the child to find the penny based on the verbal cue: "The penny is under this/that cup." The child was instructed to select one of the two cups. It was expected that the child would first be more accurate with "this" than "that" given its more proximate location and more restricted object

\footnotetext{
${ }^{5}$ Like exophoric uses, endophoric uses are non-deictic if they are accompanied early on by pointing/eye gaze, and/or are used noncontrastively.

${ }^{6}$ Although linguistic complexity is an additional factor in determining degree of markedness, it is immaterial in the case of the English demonstratives, consequent to their equivalent lexical status and similar phonetic forms.

${ }^{7}$ Space deictics, in the form of demonstratives, are typically produced earlier in development (at approximately 14 months of age) than are person deictics (approximately 2;8) (West 1986: 115; Tanz 2009: 87, 125).
} 
set, and would be more accurate with both demonstrative pronouns when both partners shared orientation to the objects. Three accurate responses for each demonstrative were considered to be systematic. Tanz (2009) used a similar design but substituted plates for cups, and candies for pennies.

The earliest unmarked use of "that" begins at approximately 1;6 and continues to 2;8 (West 1986: 115), appearing without its proximal counterpart. This age frame and use is supported by Clark (2007: 166-167; 1978: 96-97). "This" and "that" begin being used partially contrastively thereafter; between 2;8 and 3;4 (see appendix B) the demonstrative is used to refer to proximate objects from only a single, static contrast. With contrastive demonstrative use comes first instances of the marked demonstrative "this" and uses of the unmarked "that" to refer to less proximate objects. Demonstrative contrastive use becomes somewhat systematic only when socially based conversational roles are apprehended, beginning at $3 ; 0^{8}$ (Tanz 2009: 87, 125; West 1986: 115; 2010: 12). ${ }^{9}$ This is supported by West's inclusion of cognitive tasks in addition to natural speech samples. In fact, in the natural speech sample, none of West's participants produced "this" until 3;4 and the contrastive "that" was soon to follow (1986: 51). Furthermore, none of West's subjects reached systematic use of the space deictics even at 3;5, whereas person deictic use appeared to be systematic just prior to 3;0. It is obvious that contrastive demonstrative use depends substantially on recognition of speaker origo, hence in the acquisition sequence systematic contrastive uses are produced subsequently to systematic production of speaker "I" and addressee"you" (Tanz 2009: 87, 125; West 1986: 115).

Although some systematic demonstrative use is evident after 3;4, further refinements are needed to advance a full space deictic contrast-- the extent of speaker origo shifts and the extent of space orientation alterations, which initially depend upon joint attention and social reciprocal skills. Tanz's (2009: 37, 125) findings based on a similar experimental design indicate that full contrastive demonstrative use is not ascertained until 4;9. Tanz's subjects ranged in age from 3;6 to 5;0; and even at 4;1 only two thirds of her subjects were able systematically to select the appropriate plate under which a penny was hidden when the experimenter was origo. Virtually all of her younger subjects systematically selected the appropriate plate to uncover the penny when the child was the origo and especially when the child and the experimenter shared orientations to the plates. Children's use of the marked "this" in its contrastive sense with the unmarked counterpart "that" appears not to be fully deictic until rather late in development.

While in English the speaker is the only origo for demonstrative use, other linguistic systems encode additional origos such as proximal/distal objects from the addressee's perspective or from the addressee and speaker's perspective, should they share spatial orientations (Diessel 1999: 36; Burenholt 2008: 101). In English, as in many Indo-European languages, in their full fledged sense demonstratives are contrastive, indicating a distinction in distance of a referent with respect to the distance of another referent from the speaker's orientation.

At this juncture in development, at 2;1 (see appendix B), the non-deictic use is characterized by a lack of social reciprocity between potentially contrasting locations of objects and

\footnotetext{
8 Onset of the indexical use of conversational deictics "I" and "you" takes place from its earliest productions in the second year until the productive use of the symbolic functions of "I" at approximately 3;0 and precedes deictic uses of demonstrative pronouns (West 1986: 51; 2010:12; Tanz 2009: 51-52).

${ }^{9}$ Certain social competencies appear to precede more systematic deictic performance (cf. Section 3); and fullfledged systematic deictic use may materialize somewhat later in development than the social and psychological skills necessary for their extended use. This underscores the fact that competence for a skill can precede performance; but full-fledged accurate performance may indicate a graduated consciousness of shifting conversational roles.
} 
between points of orientations to those objects (Lyons 1995: 56-57; Tanz 2009: 52-60; Deissel 2006: 469; West 1986: 68). Even after 3;0 when children begin to envision themselves in other orientations and a different object of focus might result, the origo (self as point of orientation) is static (West 1986: 115; 2010: 7; Tanz 2009: 87, 125). Further evidence of the non-deictic pre-social use is that the child applies the same demonstrative to refer to objects whose distance is either more or less proximate. To rise to the level of deictic use "this" and "that" must be employed to distinguish the location of objects from self as origo as well as other as origo. To be considered deictic, on a larger scale, children must determine (however unconsciously) that the point of orientation with respect to the referent/s is not applied to self only or to another only, but to a functional role, namely, the conversational role of speaker.

\section{Apprehension of symbol in deictic use}

Early indexical gestures, even if their conventional uses are apprehended, are nonetheless non-deictic and pre-social. Gestures such as eye gaze, pointing, and the like never rise to the level of deictic use, since index never refers to particular classes (Nunberg 1993: 36-39; 1995: 111) within which a reciprocal social relationship is operational. Children's early use of gesture is primarily indexical and secondarily iconic in the Peircian sense. In pointing to the object under focus, the iconic function of indexical gestures draws attention to qualities of the object, e.g., its color, size, shape, etc., illustrating the mix of the indexical with the iconic in their early use. Indexical signs (such as space deictic use later in development) additionally give rise to symbolic functions, not merely iconic ones, such that the signifier has a dual purpose - not merely to point out an individual object, but to denote its inclusion in a class of objects.

Means to think symbolically is dependent on the development of classification skills which rests upon comparisons and contrasts. Underlying more advanced classification skills is children's competence to decenter-- to hold a minimum of two objects/qualities of objects simultaneously in memory. This skill begins developing at approximately 1;0 (Bornstein 2002: 380). Cognitive precursors to symbolic functions include separating objects into groups based upon their perceptual and functional attributes. Children's separation of objects into distinct classes based on perceptual and functional attributes is a precursor to perceiving object orientations and their distance from origo, since both depend on perceptual comparisons and contrasts. With respect to the former, two blocks may be grouped separately if they are of different colors or slightly different shapes, requiring comparisons and contrasts. With respect to the latter (orientational and distance functions) two identical blocks may be compared in terms of their relative location to origo, which requires spatial comparisons of the relative location of the objects, as well as perspective-taking (taking the relevant point of view with respect to the objects' location.) The latter orientational competence is inherent to full use of deictic contrasts and clearly rests upon symbolic representations.

Levinson (2004: 100) supports the necessity of Peirce's application of symbol to deictics, i.e., index alone does not qualify as deictic, but he fails to discuss how it is that without Peirce's semiotic characterization of symbol index falls short of deictic use. Levinson (2004: 100) acknowledges that in deixis "we have an intersection of the indexical plane into the symbolic one," but he omits any explanation of how symbolic meaning is distinctive from indexical meaning and the particular import of semiotic symbolic meaning to indexical use toward fullfledged deictic mastery. From a semiotic vantage point, symbolic signs denote a general type or set of qualities characteristic of a set of referents without necessarily having any existential relationship with the signified (CP 2.293); deictics are a special case in that they typically have both symbolic meaning and an existential relationship with the signified. The requirement of symbolic meaning in deictic use has been alluded to by Nunberg (1993: 20) 
when he refers to the "classificatory component" of strong indexicals, which in his system qualify as deictics. Nonetheless, Nunberg (1993: 20) falls short of elaborating on what he means by "classificatory." Peirce's notion of symbol informs what is meant by classificatory, namely, a general meaning, in that classes represent types, not tokens - their individuality is perceived in light of membership in a class, e.g., "this" is a proximate object (type) from speaker's perspective (or that of another origo), not just any object of focus from ego's perspective, namely, that of the child.

En route to full-fledged deictic use, apprehension of symbolic meaning is paramount. Integration of the semiotic of symbolic meaning with indexical use characterizes deictic advances, i.e., recognition of the legitimacy of several origos whose slot is filled by innumerable potential points of view; these points of view need to be perceived as having several potential orientations to potential objects. As informed by Peirce's semiotic, indexical use, social orientation and symbolic meaning are integrated and inform one another to arrive at the particular intended reference. This developmental scheme is supported by Werner and Kaplan (1963) and Karmiloff-Smith (1979). Werner and Kaplan underscore the fact that symbolic functioning is a primary benchmark toward the emergence of increased social and linguistic functioning. Demonstrative pronouns are first used non-relationally/pre-socially; and origo is static. Use of symbolic meaning together with apprehension of the shifting orientation of distinctive origos is paramount to full-fledged deictic use. What qualifies as deictic must involve apprehension of orientational and social shifts together with application of invariant meaning of a functional role (symbolic meaning). The absence of symbolic meaning in emergent uses of person and space deictics demonstrates initial pre-social productions later becoming deictic and social and still later becoming psychosocial when symbolic meaning (shifting origo, shifting orientations) characterizes the use (West 2010: 5).

\section{Conclusion}

Children's early uses of indexical gestures do not qualify as deictic in that they ignore joint attentional schemes and symbolic/semantically invariant meanings. Early linguistic indexes, especially demonstrative pronouns (accompanied or unaccompanied by gesture) are likewise non-deictic in their inception of use - they similarly ignore another semiotic classification; symbolically determined conventional roles which indicate conversational partners and other orientational objects/people as origos in their spatio-temporal milieu. Because children's early use of demonstratives is non-contrastive, and because they are used in their unmarked sense they do not qualify as deictic - their function is similar to the use of early gesture, which is indexical and pre-social. Early adherence to the non-contrastive and unmarked use demonstrates children's dependence on the indexical character of demonstratives to the exclusion of their bi-directional and symbolic function. This shifting phenomenon applies not merely to deictics of place but has a wide scope of application to use of other lexical categories, e.g., to temporal contrasts, and should be explored further.

With the apprehension of a semiotic/symbolic function, demonstrative meaning becomes deictic when they are used contrastively and when other origos are recognized. Children need repeated/sustained experiences as conversational partners (speaker/addressee/non-participant observer) and need to consider online more than one object simultaneously. Engaging in frequent conversational partnerships is an active means to validate and consolidate the symbolic, functional roles of each participant, together with recognition of relative spatial distance and orientations with respect to contextually relevant objects, as in role-play and representational play. (Cf. West 2010 for further discussion of the role of representational play in the acquisition of deictic terms.) When children use demonstratives contrastively, speaker as point of orientation and relative placement of objects with respect to speaker are apprehended. Still further along in development children apprehend non-speaker (addressee 
and non-speech partners) as origo and object orientations with respect to such roles. This latest advance illustrates children's use of joint attentional and other social skills toward perspective-taking competencies which are psychosocial in nature - means to transcend ego's, speakers and even addressees points of orientation to objects. Identifying when deictic use emerges helps to determine children's degree of social and symbolic functioning determining not merely use of the demonstrative pronouns as index but determining the emergence of deictics to identify orientational groundedness with respect to distinctive objects.

\section{References}

Bates, Elizabeth (1976): Language and context: The acquisition of pragmatics. New York: Academic Press.

Bates, Elizabeth (1979): The emergence of symbols: Cognition and communication in infancy. New York: Academic Press.

Bornstein, Marc H. (2002): Handbook of parenting and becoming a parent (Vol. 3). Mahwah, New Jersey: Lawrence Erlbaum \& Associates.

Butterworth, George/Jarrett, Nicholas (1991): "What minds have in common is space: Spatial mechanisms serving joint visual attention in infancy". British Journal of Developmental Psychology 9: 55-72.

Butterworth, George (1995): "Origins of Mind in Perception and Action". In: Moore, C./Dunham, P. (eds.): Joint Attention: Its Origins and Role in Development. New Jersey, Lawrence Erlbaum Associates: 29-40.

Bühler, Karl (1932/1990): Theory of language: The representational function of language. Amsterdam: John Benjamins Publishing Company.

Burenholt, Niclas (2008): "Spatial coordinate systems in demonstrative meaning". Linguistic Typology 12: 99-142.

Carpenter, Robert L./Mastergeorge, Ann M./Coggins, Truman E. (1983): "The acquisition of communicative intentions in infants eight to fifteen months of age". Language and Speech, 26: $101-116$.

Carpenter, Malinda/Nagell, Katherine/Tomasello, Michael (1998): "Social cognition, joint attention, and communicative competence from 9 to 15 months of age". Monographs of the Society for Research in Child Development, Serial 255, 63 (4).

Clark, Eve V. (1978): "From gesture to word: on the natural history of deixis in language acquistion". In: J.S. Bruner and A. Garton (eds.): Human growth and development. Oxford, Oxford University Press: 85-120.

Clark, Eve V. (2003): First language acquisition. Cambridge: University of Cambridge Press.

Clark, Eve V. (2007): "Young children's uptake of new words in conversation." Language and Society (36) 2: 157-182.

Clark, Eve V. (2009): First language acquisition (2 ${ }^{\text {nd }}$ ed.). New York: Cambridge University.

Crais, Elizabeth/Douglas, Diane Day/Campbell, Cheryl Cox (2004): "The intersection of the development of gestures and intentionality". Journal of Speech, Language, and Hearing Research 47: 678-694.

Diessel, Holger (1999): Demonstratives: Form, function, and grammaticalization. Philadelphia: John Benjamins Publishing Company.

Diessel, Holger (2006): "Demonstratives, joint attention, and the emergence of grammar". Cognitive Linguistics (17) 4: 463-489.

Fricke, Ellen (2002): "Origo, pointing, and speech: the impact of co-speech gestures on linguistic deixis theory". Gesture (2) 2: 207-226.

Goldin-Meadow, Susan (2003): Hearing gesture: How hands help us think. Cambridge, MA \& London: The Belknap Press of Harvard University Press. 
Karmiloff-Smith, Annette (1979): A functional approach to child language: A study of determiners and reference. Cambridge: Cambridge University Press.

Haviland, John (2000): "Pointing, gesture spaces, and mental maps". In: David McNeill (ed.): Language and gesture. Cambridge, Cambridge University Press: 13-46.

Halliday, M.A.K./Hasan, Ruqaiya. (1976): Cohesion in English. London: Longman Group.

Levinson, S.C./Kita, Sotara/Hauna, Daniel B.M./Rasch, Björn H. (2002): "Returning the tables: language affects spatial reasoning". Cognition 84: 155-188.

Levinson, S.C. (2004): "Deixis and Pragmatics". In: Horn, Laurence/Ward, Gregory (eds.): The handbook of pragmatics. Oxford, Blackwell: 97-121.

Lyons, John. (1968): Introduction to theoretical linguistics. New York: Cambridge University Press.

Lyons, John (1977): Semantics, Volume 1. Cambridge: Cambridge University Press.

Lyons, John (1995): Linguistic semantics: An introduction. Cambridge: Cambridge University Press.

Nunberg, Geoffrey (1993): "Indexicality and deixis". Linguistics and Philosophy 16: 1-43.

Nunberg, Geoffrey (1995): "Transfers of meaning". Journal of Semantics 12: 109-132.

Peirce, Charles S. (1868): "Questions concerning certain faculties claimed for man". Journal of Speculative Philosophy 2: 103-114. Available at http://www.peirce.org/writings/ p26.html, accessed November 2011.

Peirce, Charles S. (1955): Philosophical writings of Peirce. Justus Buchler, (Ed.). New York: Dover Press.

Peirce, Charles S. (1931-1966): Collected Papers of Charles Sanders Peirce. Vols. 1-6 edited by C. Hartshorne: Weiss. Cambridge, Massachusetts: Harvard University Press. Vols. 7-8 edited by A. Burks. Cambridge, Massachusetts: Harvard University Press.

Pizzuto, Elena Antinoro/Copabianco, Micaela (2005): "The link and differences between deixis and symbols in children's early gestural-vocal system". Gesture (5)1/2: 79-99.

Pizzuto, Elena Antinoro/Capobianco, Micaela (2008): "Is pointing 'just' pointing?" Gesture 1: 82-103.

Povinelli, Daniel J./Bering, Jesse M./Giambrone, Steve (2004): "Chimpanzees pointing? Another error by analogy". In: Kita, Sotaro (Ed.): Pointing: Where language, culture, and cognition meet. New Jersey, Lawrence Erlbaum Associates: 35-68.

Scaife, Michael/Bruner, Jerome S. (1975): "The capacity for joint visual attention in the infant". Nature 254, 5489: 256-266.

Tanz, Christine (2009): Studies in the Acquisition of Deictic Terms. London: Cambridge University Press.

Thal Donna/Tobias, Stacy (1992): "Relationships between language and gesture in normal and late-talking toddlers". Journal of Speech and Hearing Research 37: 151-171.

Volterra, Virginia/Caselli, Maria C./Capirci, Olga/Pizzuto, Elena (2005): "Gesture and the emergence and development of language". In: Tomasello, Michael/Slobin, Dan (eds.): Beyond nature-nurture: Essays in honor of Elizabeth Bates. New Jersey, Lawrence Erlbaum Associates: 3-40.

Werner, H./Kaplan, B. (1963): Symbol formation. New York: Wiley and Sons.

West, Donna E. (1986): The Acquisition of Person and Space Deictics: A Comparison Between Blind and Sighted Children. Unpublished Doctoral Dissertation, Cornell University.

West, Donna E. (1987): "The Critical Function of Tactile Index in Blind Children's Use of Deictics". In: John Deely (ed.): Semiotics 1987. New York, University Press of America: $128-141$.

West, Donna E. (1988): "Form and Use Differences in the Acquisition of Speech Participant Signifiers: Evidence from Blind Children". In: Terry Prewit/Deely, John/Haworth, Karen (eds.): Semiotics 1988. New York, University Press of America: 38-52. 
West, Donna E. (2010): "Person deictics and the imagination: their metaphoric use in representational play". California Linguistic Notes (35) 1: 1-25.

West, Donna E. (2011): "Indexical reference to absent objects: Extensions of the Peircian notion of index". In: Prewitt, T./Haworth, K. (eds.): Semiotics 2010. New York, University Press of America: 153-165.

Zinober, Brenda/Martlew, Maragaret (1985): "Developmental changes in four types of gesture in relation to acts and vocalizations from 10 to 21 months." British Journal of Developmental Psychology 3: 293-306.

\section{Appendix A}

\begin{tabular}{|c|c|c|c|c|}
\hline AGES & $0 ; 0-0 ; 4$ & $0 ; 4-0 ; 8$ & $0 ; 8-1 ; 2$ & $1 ; 2-1 ; 6$ \\
\hline PROTO GESTURE & $\begin{array}{l}\text { Eye gaze follows } \\
\text { another's alteration } \\
\text { in gaze orientation }{ }^{10}\end{array}$ & & & \\
\hline $\begin{array}{l}\text { PRE-SOCIAL } \\
\text { GESTURE }\end{array}$ & & $\begin{array}{l}\text { Eye gaze } \\
\text { coordinates with } \\
\text { grasping in joint } \\
\text { attentional scheme }\end{array}$ & & \\
\hline $\begin{array}{l}\text { SOCIAL } \\
\text { GESTURE }\end{array}$ & & & $\begin{array}{l}\text { Eye gaze } \\
\text { coordinates with } \\
\text { extending the arm } \\
\text { and hand in giving } \\
\text { exchanges }^{12}\end{array}$ & $\begin{array}{l}\text { Eye gaze without } \\
\text { any other } \\
\text { accompanying } \\
\text { gesture to secure } \\
\text { joint attention }{ }^{13}\end{array}$ \\
\hline
\end{tabular}

Pre-deictic uses of indexical gestures

\section{Appendix B}

\begin{tabular}{|l|l|l|l|}
\hline AGE & USE & $\begin{array}{l}\text { LOCATION CONTRAST OF } \\
\text { OBJECTS }\end{array}$ & $\begin{array}{l}\text { ORIENTATION } \\
\text { CONTRAST/PERSPECTIVES }\end{array}$ \\
\hline$-2 ; 8$ & Indexical, non deictic & "that" only without contrast & $\begin{array}{l}\text { Point of orientation } \\
\text { unrecognized }\end{array}$ \\
\hline $3 ; 8-3 ; 4$ & Indexical, non deictic & $\begin{array}{l}\text { "this" } 66 \% \text { accuracy, "that" } \\
55 \% \text { accuracy }\end{array}$ & Single static self orientation \\
\hline $4 ; 1-4 ; 8$ & $\begin{array}{l}\text { Indexical-Symbolic, } \\
\text { deictic }\end{array}$ & $\begin{array}{l}\text { "this" } 83 \% \text { accuracy, "that" } \\
50 \% \text { accuracy }\end{array}$ & Orientation self and other \\
\hline $43 \%$ accuracy & $\begin{array}{l}\text { Indexical-Symbolic, } \\
\text { deictic }\end{array}$ & $\begin{array}{l}\text { "this" } 100 \% \text { accuracy, "that" } \\
90 \% \text { accuracy }\end{array}$ & Orientation self and other \\
\hline $48+$
\end{tabular}

Non-deictic to deictic use of demonstratives by age (Ages derived from West's (1986) data and Tanz's (2009) data.)

\footnotetext{
10 Scaife \& Bruner 1975: 265.

11 Butterworth 1995: 37.

12 Carpenter, Nagell \& Tomasello 1998: 147.

13 Butterworth \& Jarrett 1991: 63.
} 